\title{
ESTIMATION OF FLASH FLOOD HAZARD IN THE PIDIMA- ARFARA AREA (MESSINIA, SW GREECE), BASED ON THE STUDY OF INSTANTANEOUS UNITARY HYDROGRAPHS, LONGITUDINAL PROFILES AND STREAM POWER
}

\author{
Sambaziotis E. ${ }^{1}$, and Fountoulis $\mathbf{I}^{1}$ \\ ${ }^{I}$ National and Kapodistrian University of Athens, Faculty of Geology and Geoenvironment, \\ Department of Dynamic Tectonic Applied Geology,fountoulis@geol.uoa.gr
}

\begin{abstract}
In this paper it is an effort to combine different methodologies in order to locate the sensitive sites in flash flood phenomena in a relatively small catchment located north of Kalamata (Messinia SW Peloponnese, Greece). Based on digitised topographic map (scale 1/5.000) the longitudinal, gradient and stream power profiles of the watercourses were constructed and the results (possibly sensitive to flash floods sites) were compared to ones that came from applying hydrological simulation, hydrographs as well as Instantaneous Unitary Hydrographs. The comparison showed that the results were in good agreement.
\end{abstract}

Key words: slope gradient, flash flood, longitudinal profile, Instantaneous unit Hydrograph.

\section{Пвріं}

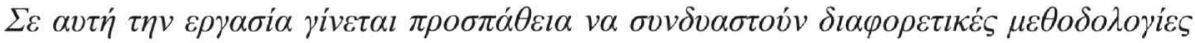

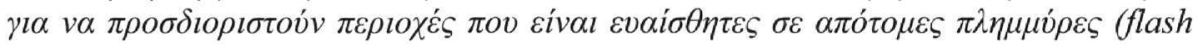

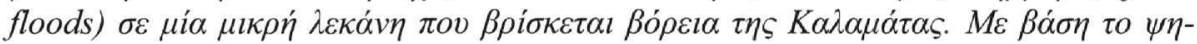

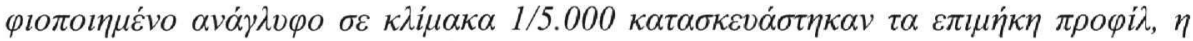

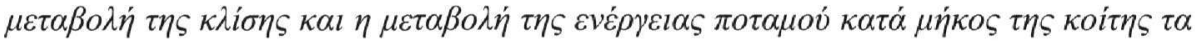

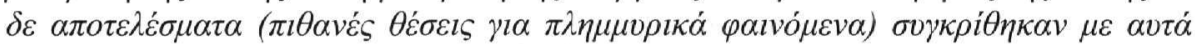

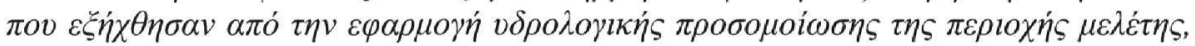

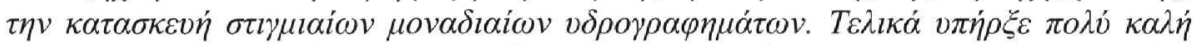

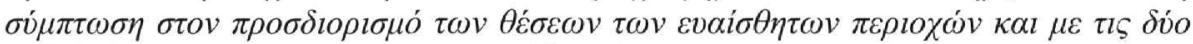

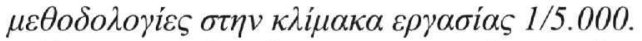

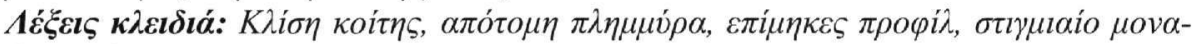

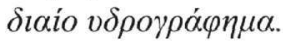

\section{Introduction}

Rainfall - runoff modelling in arid and semi-arid region catchments is rendered challenging because of environmental heterogeneity in space and time, wich results in the production of irregular and extreme flood events. In semi-arid regions catchments rainfall usually takes place over small portions of catchments. Accordingly, the runoff produced over the upstream areas where rainfall occurs must be translated to downstream sites through the main channel and its tributaries. 
In the broader Kalamata area many flash flood phenomena have taken place, such as in November 4, 1924 (Kalamata), November 19, 1979, in November 18, 1983, in November 24, 1985, in November 7, 1991, in November 21, 1993 (Mani). During the 1924 flood of Nedon River that crosses the city of Kalamata, 15 people lost their lives. Except these historically flash flood phenomena, well-rounded large blocks (1-1.5 $\mathrm{m}$ in diameter) along the active channel of Kaminakias catchment, as well as on the lower terrace occur, in the Arfara-Pidima (north of Kalamata) area. The occurrence of these blocks shows that they have been transported by the stream from higher elevated areas in combination with the intense rainfalls that occasionally have taken place in the region and it reinforced by the information coming from the village residents that, when the stream fills with rainwater, it takes place very abruptly and with enough noise. All these forced us to believe that this particular area requires particular attention. Occasionally have been attempted certain interventions in the watercourse (regular cleaning and support of the channel banks especially close to houses) that have decreased but not eliminated the problem. The need to study the hazard resulting from floods in this area was the initial reason to try to apply different approaches as there is a general problem in the Greek territory with rainfall intensity measurements as well as discharge measurements in the best case are very poor, or do not exist.

In this paper it is tried to combine and to evaluate data coming from the geomorphology (slope gradient map, longitudinal profiles of the streams and stream-catchment ordering following the Strahler ordering procedure), and Stream Power calculation, and to compare the results with the ones coming from the study of the Instantaneous Unitary Hydrographs (IUH) in a relatively small catchment area, the Kaminakias catchment.

The study area located at the NW margins of Taygetos Mountain north of Kalamata consists the transition zone between the Kato Messinia graben and the Taygetos Mt. Horst (Mariolakos et al. 2001) present a relief, which is mainly steep due to the occurrence of active faults and only in the basin area, is relatively planar. From the morphological point of view, the study area presents high angle slopes and its elevation ranges from $16 \mathrm{~m}$ in the Pidima area to $1272 \mathrm{~m}$ in the Vromovrisseika Mts. As it shown in slope gradient map (Fig. 1) there are zones with high slope gradient related to the active fault escarpments. The construction of the slope gradient map, Kaminakias drainage network and watershed, longitudinal profiles etc. were based on 6 digitised topographic sheets in scale $1 / 5.000$.

On the slope gradient map (Fig. 1) the sites with abrupt changes, which are signed with black arrows show the areas with the higher slope gradient. In the same map intense incision zones developed parallel to parts of the streams that have been formed in E-W direction and transversal to the active faults trend. The Kaminakias drainage network is a $4^{\text {th }}$ order according to Strahler ordering procedures and the catchment has a $30,21 \mathrm{~km}^{2}$ area.

\section{Longitudinal profiles along the main streams of Kaminakias drainage network and Stream power calculation}

The main factors controlling the morphological characteristics of the streams are: the gradient of the watercourse, the isolation of the stream network, the hydrologic characteristics and the flood history, the type and the quantity of the transported materials, the vegetation and the human factor. Generally, the first three of them change systematically along watercourse from upstream to downstream in each river-stream system. In humid environments when stream gradient decreases, the discharge increases and the drainage network becomes more isolated as the rivers enter in their coastal or alluvium areas. Even if the geological factors involve important local exceptions in these general tendencies, shown very well on the longitudinal profiles, the main reason are the changes of these variables that already mentioned, along the watercourse, which cause significant changes in the morphology that it is obvious in all river-stream systems (Knighton 1999). 
Knighton (1999) assumed that in order to determine the tendencies of the Stream Power, along the watercourse: "the problem of modelling the changes of the gradient from upstream to downstream of the watercourse, has to do with the finding of the suitable equation for the profiles". The basic problem to determine tendencies of the Stream Power, along the watercourse, according to Knighton (1999) is the modelling of the changes of the gradient from upstream to downstream, along the watercourse, which is now very easy with the use of G. I. S software, at least in environments of high relief. This becomes with the utilisation of high analysis digital elevation models (DEMs) resulting from digitised topographic maps. Thus, the aim is to apply a simple method and based on this method, the longitudinal profiles of the watercourses, the total and specific energy of river, in various watersheds, can be modelled using DEM (Digital Elevation Model), as well as local relations between the watershed and the discharge. Thus might explain itself the advantages and the likely applications of this type of modelling, in order to locate and solve, as long as it is possible, the individual problems (localisation of regions that are sensitive in flood phenomena) that might exist.

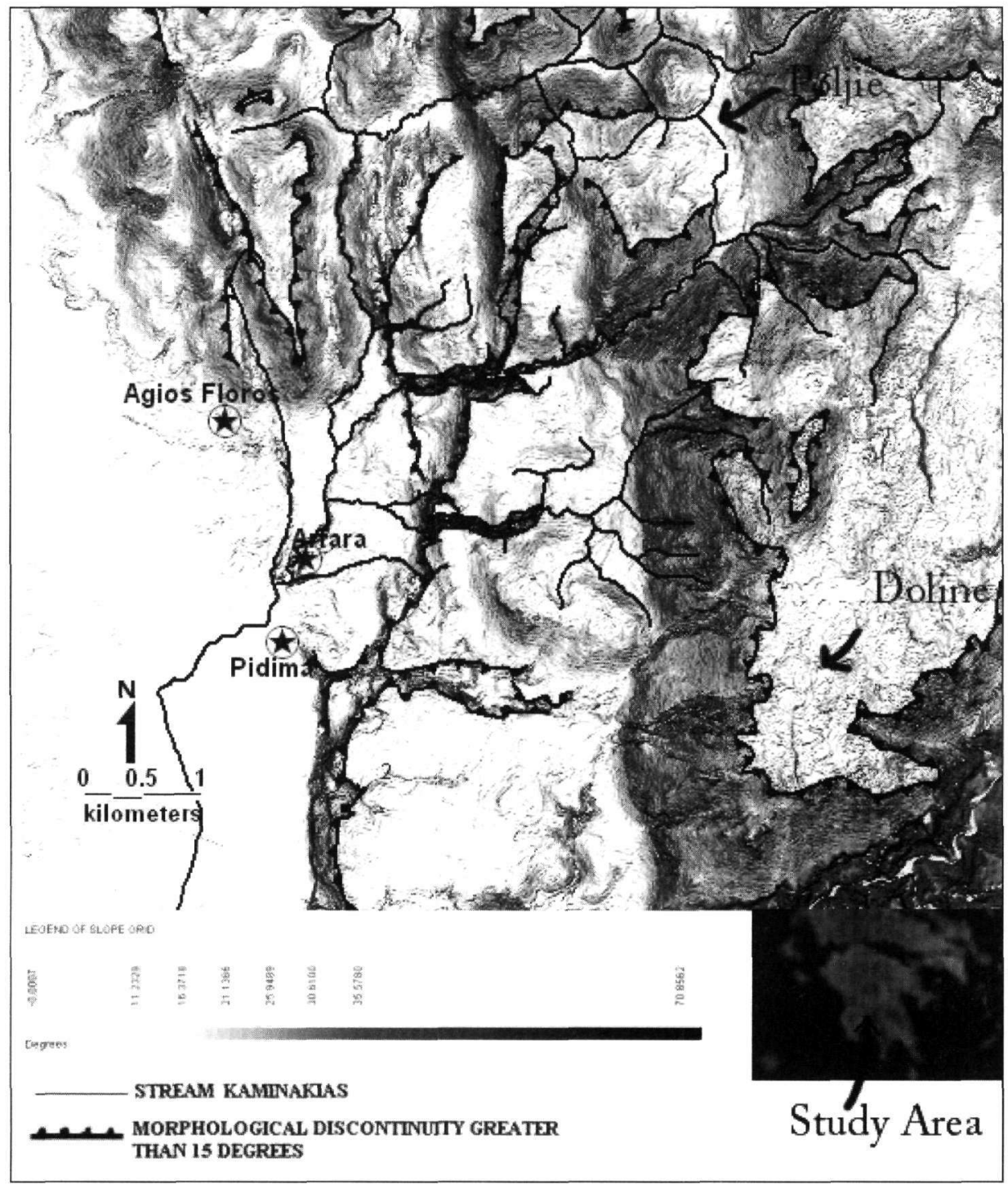

Figure 1 - Slope gradient map 
Kaminakias drainage network starts from the Vromovriseika Mountains, passes through the village of Arfara and then it is linked with river Aris that springs from the Pidima springs. The watershed can be divided in three $3^{\text {rd }}$ order basins that form the $4^{\text {th }}$ order Kaminakia catchment. The watershed occupies $30.21 \mathrm{~km}^{2}$ area and consists mainly of intensively karstified Cretaceous carbonates of the Tripolis unit.

Based on the produced TIN we were able to export six (6) longitudinal profiles along the Kaminakias watercourse sectors of the catchment as well as the gradient profiles for the same sectors (Fig. 2). Finally with the use of the formula: $\boldsymbol{\Omega}=\mathbf{g} \mathbf{Q S}$, where $\boldsymbol{\Omega}$ is the total Stream Power per length unit $\left(\mathbf{W} * \mathrm{~m}^{-1}\right)$ where $\mathbf{W}$ in watt, $\mathbf{g}$ is the specific weight of water $\left(9807 \mathrm{~N}^{-2} \mathrm{~m}^{-2}\right), \mathbf{Q}$ is the discharge $\left(\mathrm{m}^{3} / \mathrm{s}\right)$ and $\mathbf{S}$ is the active bent, Stream Power profiles were respectively produced. The localisation of the sensitive areas was based on the combined evaluation of the longitudinal and the Stream Power profiles.

For studies concerning morphological changes along the watercourse of a torrent for river systems, it is useful to express the longitudinal profiles in the form of gradient due to the known effect of the channel gradient in the morphology of the watercourse (e.g. Schumm 1985, Grant et al. 1990, Montgomery and Buffington 1997). The approach of the "vertical parts" for the simulation of the change of gradient along the watercourse gives us an explicit segregation between the points with higher and lower gradient for small intervals in the beginning of the torrent and in the middle of the distance of straight parts between the turns that makes the drainage network.

More specifically, in order to calculate the Stream Power, data of the stream discharges are needed. However, such data do not exist and for this reason, we decided to use the daily rain data from the rain stations of Pidima and Agrilos located within the Kaminakias watershed, for the period 1945-2003. The daily rainfall heights data that were over (no lower) $40 \mathrm{~mm} /$ day were ordered from the higher to lower. The highest value for the period $1945-2003$ was $145.5 \mathrm{~mm}$. We assumed the $100 \%$, of the highest daily rainfall corresponds to the watercourse discharge (runoff), although it is known that generally a part of the amount of rainfall consist the discharge of the watercourse and the other is infiltrated to the ground or/and is evaporated. But, in environments, with no or low vegetation, intense relief, and heavy rain (extreme events) we assume that the amount of the rain that can be evaporated or infiltrated is bare and the carbonates behave like impermeable rocks during heavy rainfalls. Thus the values of rainfall are related to the time and applying the formula: Q $=\mathrm{V} / \mathrm{t}($ Volume/time $)=\mathrm{Eh} / \mathrm{t}$, and the $\mathrm{h} / \mathrm{t}$ corresponds to the daily rainfall (Sherman 1932 , Lee 1998).

Consequently, for discharge corresponding to $100 \%$ rainfall $145.5 \mathrm{~mm} /$ day the values are:

\section{$\mathrm{Q}=\mathbf{5 1 . 3 6} \mathrm{m}^{3} / \mathrm{sec}$ and $\Omega=371504.18 \cdot \mathrm{S}(\mathrm{W} / \mathrm{m})$}

According to the above values and having as variable $\mathbf{S}$, which is the active gradient in each point of the watercourse, the Stream Power profiles were constructed respectively, related to the distance from the lower elevated point. Following for the calculations we assumed discharge $Q=51.36$ $\mathrm{m}^{3} / \mathrm{sec}$ corresponding to $145.5 \mathrm{~mm} /$ day rainfall that is $100 \%$ rainfall as the evaporation and the infiltration were not taken into account. Following we present some comments for some selected profiles:

Profile 1 shows a concave profile where the highest values of gradient are observed in the higher elevated points, where the stream power is also increased, and declines downstream (Fig. 3). In the point that the profile passes from high to low gradient values and stream power is increased, in a distance about $1200 \mathrm{~m}$ from the starting point, it is the area in which an active fault occur consisting the boundary between the Tripolis unit carbonates and the Pleistocene marine deposits.

Profile 2, which is more complex than profile 1 shows higher values of gradient, which are observed neither to the middle nor to the end of the profile, at the points that the profile crosses the occurring faults (Fig. 3). In these points Stream Power increases its values from $28.409,51 \mathrm{~W} / \mathrm{m}$ to 
$243.773,1 \mathrm{~W} / \mathrm{m}$ in a distance of $199 \mathrm{~m}$ (from $806 \mathrm{~m}$ until $1.005 \mathrm{~m}$ ) that is $858 \%$ Stream Power increase. In the point that gradient changes, in a distance about $1000 \mathrm{~m}$ from the starting point, it is the area in which an active fault occurs consisting the boundary between the Tripolis unit carbonates and the Pleistocene marine deposits.

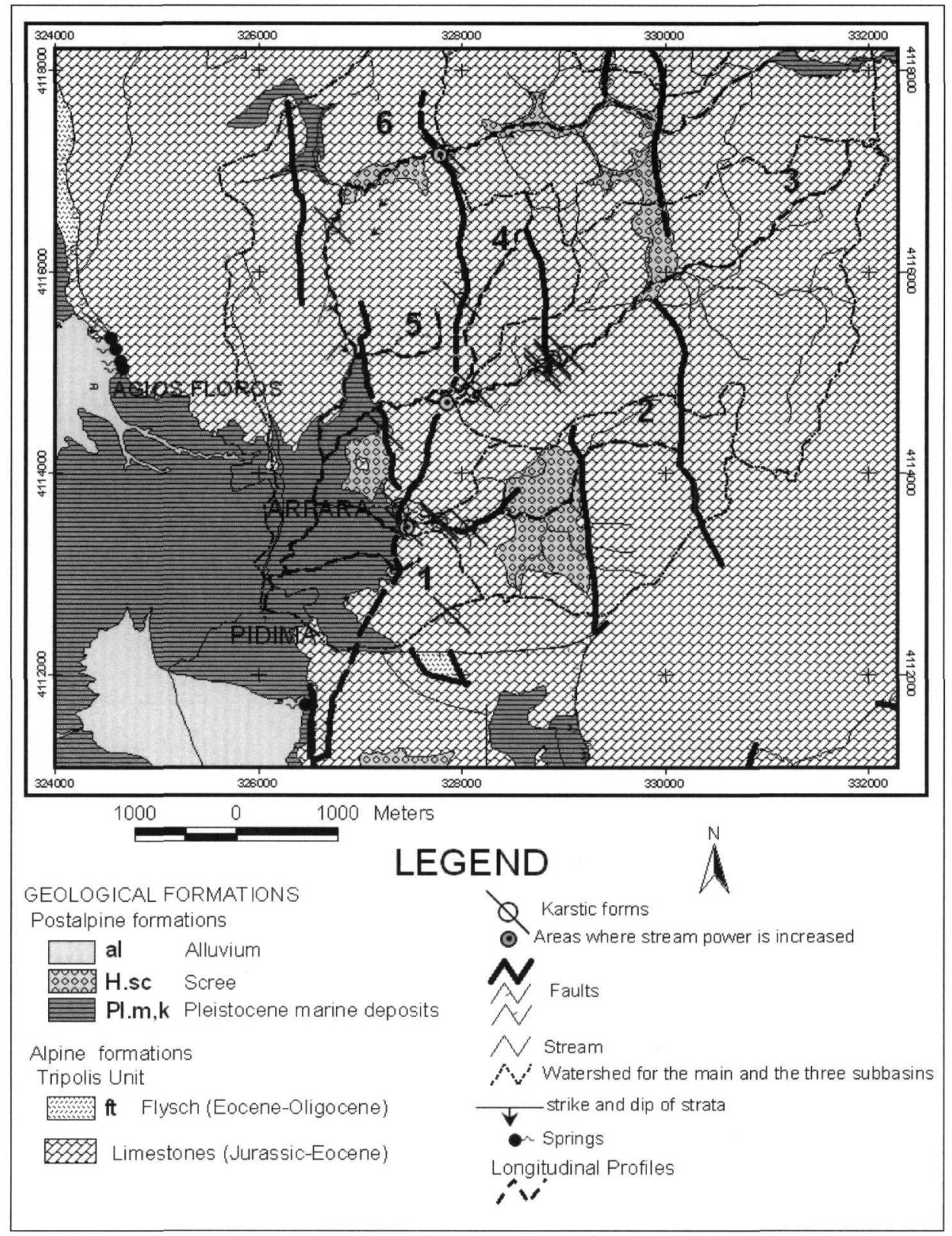

Figure 2 - Geological map of the study area with the locations of the longitudinal profiles

Profile 3, which present some similarities with profile 2 shows higher values gradient, which are observed neither to the middle nor to the end of the profile, at the points that the profile crosses the occurring faults (Fig. 4). In these points there are two major increases of the Stream Power: a) increases its values from $24.559,27 \mathrm{w} / \mathrm{m}$ in $130.443,8 \mathrm{w} / \mathrm{m}$ in a distance of $370 \mathrm{~m}$ (from $2.659 \mathrm{~m}$ until $3.030 \mathrm{~m}$ ) and b) increases its values from $35.703,34 \mathrm{w} / \mathrm{m}$ to $116.388,2 \mathrm{w} / \mathrm{m}$ in a distance of $354 \mathrm{~m}$ (from $2.095 \mathrm{~m}$ to $1741 \mathrm{~m}$ ) that is $531 \%$ and $326 \%$ Stream Power increase respectively. 
However, on the contrary to profile 2 it presents neither so much high gradient values nor so much abrupt changes. In the point that gradient changes, in a distance about $1700 \mathrm{~m}$ from the starting point, it is the area in which an active fault occurs consisting the boundary between the Tripolis unit carbonates and the Pleistocene marine deposits.

Profile1
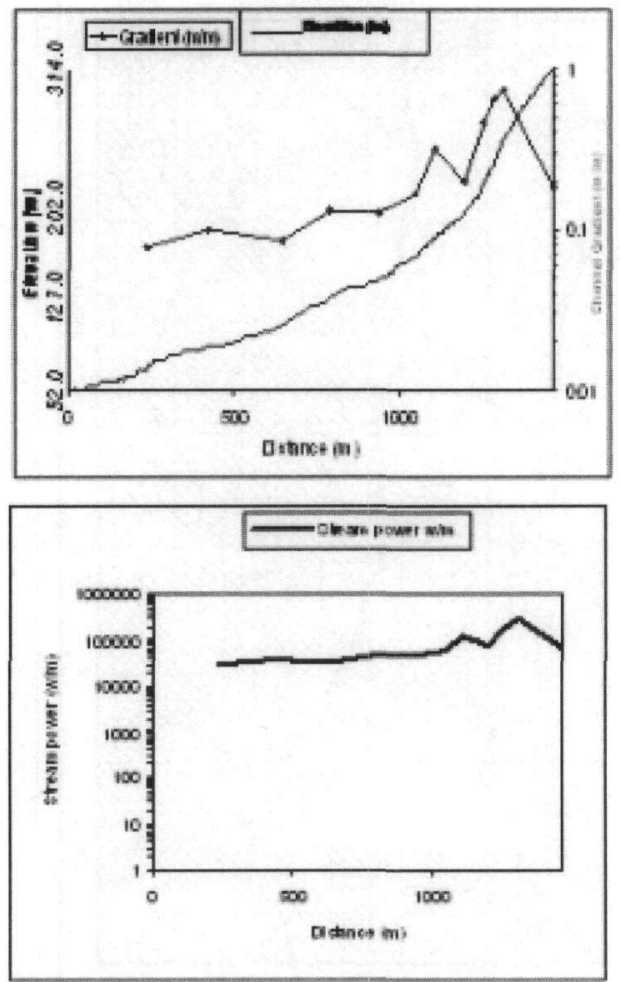

Profile2
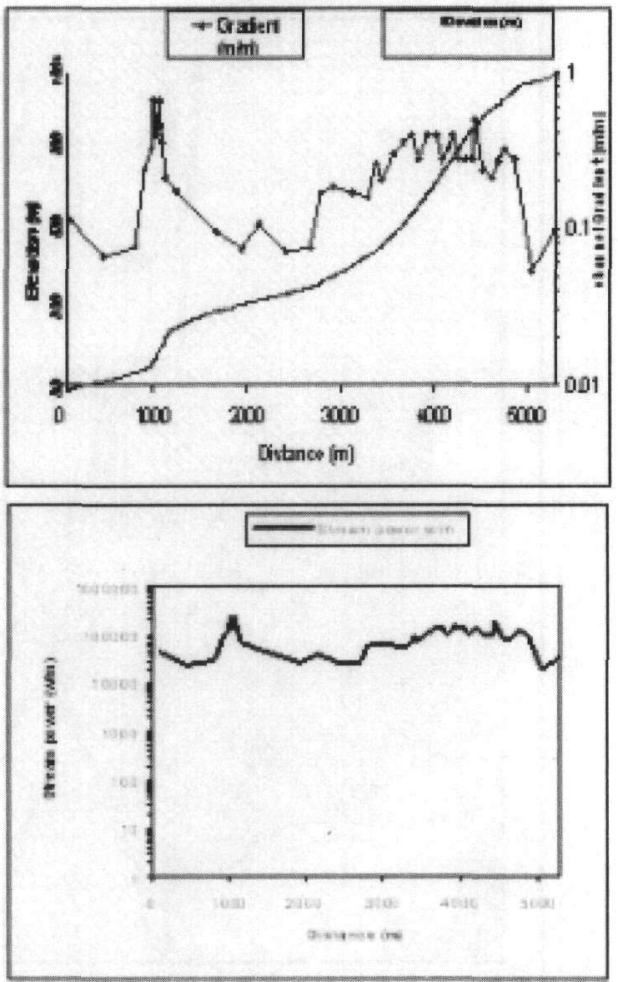

Figure 3 - Longitudinal Gradient -Distance and Stream Power - Distance profiles (the locations of the profiles are depicted in Fig. 2). The stream power rises when the gradient values increase abruptly, especially at lower altitudes that the runoff is higher as shown in profile 2

Profile 4, shows a convexity with increased gradient values along the whole profile, something that implies the youth of this tributary (Fig. 4). The same also takes place with the stream power, which gradually increases up to the end of the profile. It has to be mentioned that profile 4 is traverse to the prolongation of the Pidima active fault (Fig. 2), something that possibly can explain the convexity of the longitudinal profile (young). The profile crosses the Tripoli unit carbonates.

Profile 5 presents also as profile 4 a convexity with increased gradient values along the whole profile as well as increased stream power values, something that implies the youth of this tributary (Fig. 5). At this point it should be mentioned that profile 5 is also traverse and enough close to the prolongation of the Pidima active fault area of (Fig. 2), something that possibly can explain the convexity of the longitudinal profile. The profile crosses the Tripoli unit carbonates.

Profile 6 that present some similarities with 2 and 3 profiles as it shows higher values of gradient, which are observed neither to the middle nor to the end of the profile, in the points that the profile crosses the occurring faults (Fig. 5). On the contrary to profiles 2 and 3, it presents a very intense and abrupt change of gradient that is also the highest, which can be observed in the area. In this point a very abrupt increase of the stream power value is observed, something that it is reasonable once the stream power is proportional to the active gradient. More specifically, he Total Stream Power increases its values from $25.492,96 \mathrm{~W} / \mathrm{m}$ to $369.830,7 \mathrm{~W} / \mathrm{m}$ in a distance of $821 \mathrm{~m}$ (from 
$5.427 \mathrm{~m}$ distance to $6.248 \mathrm{~m}$ ) that is $1450 \%$ Stream Power increase. In the area where the gradient and the energy are increased, Tripolis unit carbonates as well as active faults occur.

Profile 3
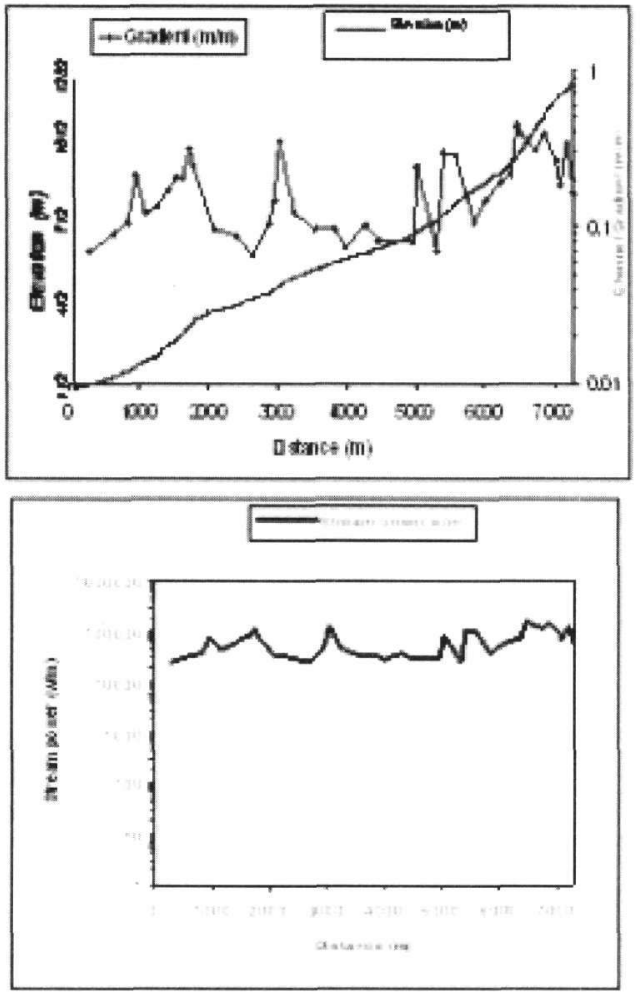

Profile 4
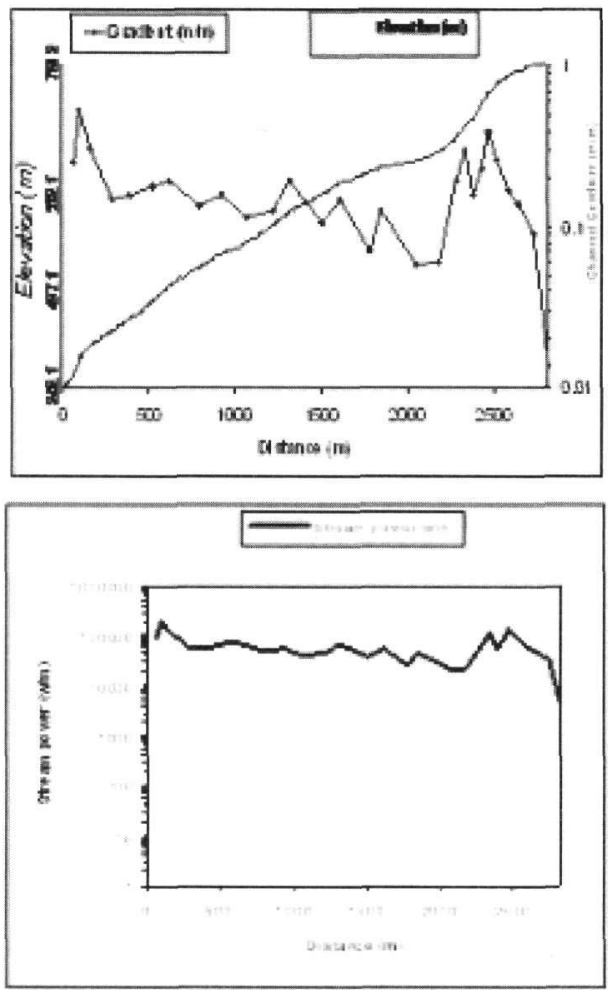

Figure 4 - Longitudinal Gradient -Distance and Stream Power - Distance profiles (the locations of the profiles are depicted in Fig. 2). The stream power rises when the gradient values increase abruptly, especially at lower altitudes that the runoff is higher as shown in profile 4

Taking into account the above mentioned, it is obvious that the abrupt increases of the stream power values are due to the abrupt increase of the gradient.

Such high abrupt increases of the stream power values can cause floods in a potential powerful rainfall, in case in these points there is also accumulation of water. Whether in these points it exists respectively also abrupt accumulation of water is something that will be presented in the hydrologic simulation paragraph that follows.

For the Hydrological simulation realization, the DEM of the Kaminakias basin was constructed based as already said on the topographic maps (scale 1/5.000). Then, the flooding technique was applied (Jenson and Dominique 1988, Sambaziotis 2005) in order to estimate the flow direction on the earth's surface of a theoretical rainfall. The above algorithm is incorporated in the extension Spatial Analyst 1.1 of ArcView GIS 3.2 (ESRI 1996). The result is a map in which the water flow directions of the rainfall are depicted by eight chromatic nuances that correspond in the eight likely flow directions of the algorithm $(1,2,4,8,16,32,64,128$ - NE, E, SE, S, SW, W, NW, N respectively). For the better presentation of the results the above values were reduced in vectors that show the possible flow direction in each individual pixel of the DEM.

Based on the already presented longitudinal profiles of the watercourses with the highest and most abrupt gradient changes, the 3 sub-basins were located and corresponding as follows: profile 6 to sub-basin 1, profile 3 to sub-basin 2 and profile 2 to sub-basin 3 (Figs 2, 7). 
The water flow direction as well as the length of the water flow directions resulted from the high resolution DEM of the study area and as the study of the accumulation of water flows showed that they coincide with drainage network derived from the topographic maps (scale 1/5.000) (Fig. 6).

Profile 5
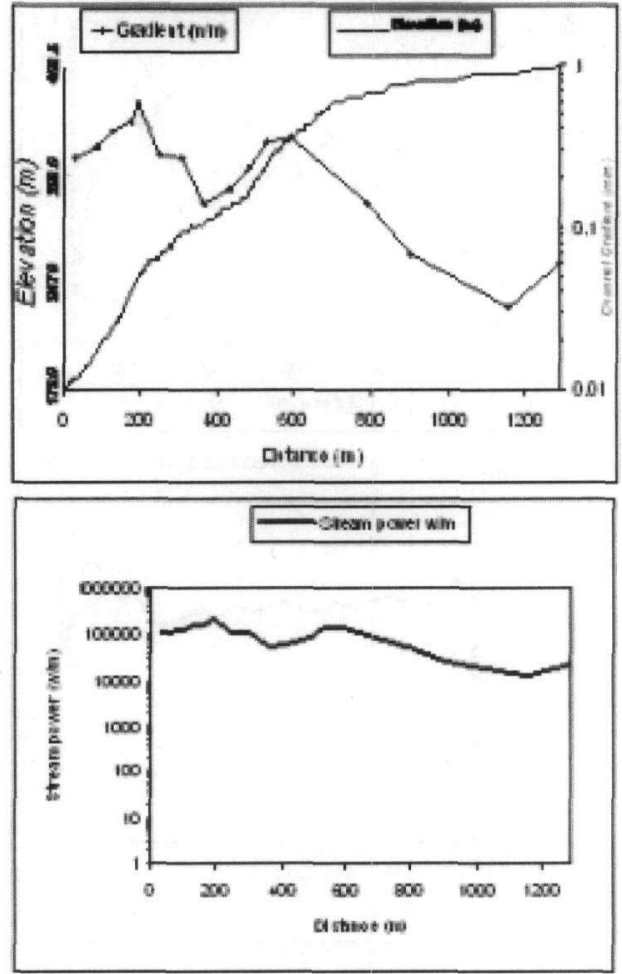

Profile 6
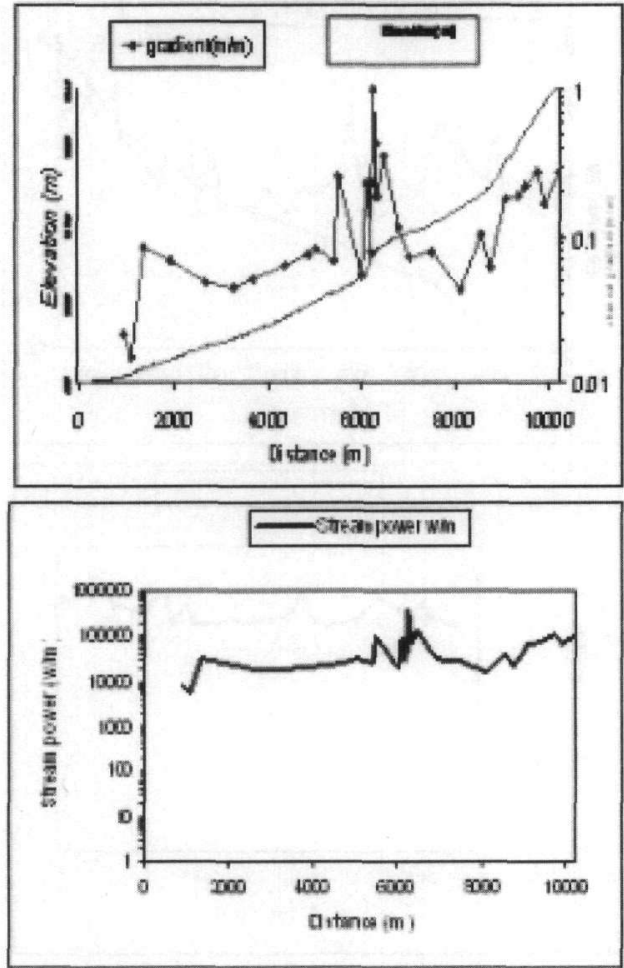

Figure 5 - Longitudinal Gradient -Distance and Stream Power - Distance profiles (the locations of the profiles are depicted in Fig. 2)

Water supply of a stream in a given site is the change of the water quantity in the unit of time and is measured in $\mathrm{m}^{3} / \mathrm{sec}$ and the diagram water supply - time is named hydrograph. The form of a hydrograph created by a rainfall of small relatively duration, that take place in a watershed, presents a general connoid form and in case this hydrograph is related to a concrete flood episode, it is named floodgraph.

Sherman (1932), used for first time in the hydrological analysis the term Unit Hydrograph (UH), aiming to the estimation of the flood peak at the cross-correlation of the hydrograph with the rainfall that caused it. Unitary hydrograph is a hydrograph that is created by active rain of height equal with the unit (e.g. $1 \mathrm{~mm}$ or $1 \mathrm{~cm}$ ) that take place in all the watershed area and has uniform intensity. The technique of UH is partly empiric and theoretical. Practically, the cross-correlation between active rainfall and surface flow is aimed. The construction of the UH of a watershed is based on natural hydrographs and on the determination of a typical rainfall duration. This technique allows, the adaptation with various techniques of UH in other episodes of rainfall of different duration and intensity and the calculation of expected flow.

The Instantaneous Unit Hydrograph (IUH) is an extension of UH and corresponds to the hydrograph produced from an instantaneous application of unitary beneficial rain in a watershed. The IUH consists the unique way for representation of a basin reaction in an episode of rainfall, independently from the duration and its intensity. As IUH does not depend on the time, it is a graphic 
expression of the resultant of all parameters of a watershed, as length, form, bas-relief, etc, that determines the above reaction.

In the last years with the development of GIS and with other more specialised software's, UH and their variants result from the surface flow simulation in the drainage network basins (Lee 1998). Following this way the reception of parameters is avoided, the values of which are also influenced with others, as well as morphometric factors that many times are insufficient to express the characteristics of those basins mainly presenting various types of asymmetries. Finally, independently the technique is applied; the main objective is the investigation of the relation rain - water flow that is defined from the reaction of a basin in rainfall episodes and the estimation of the flood potential.
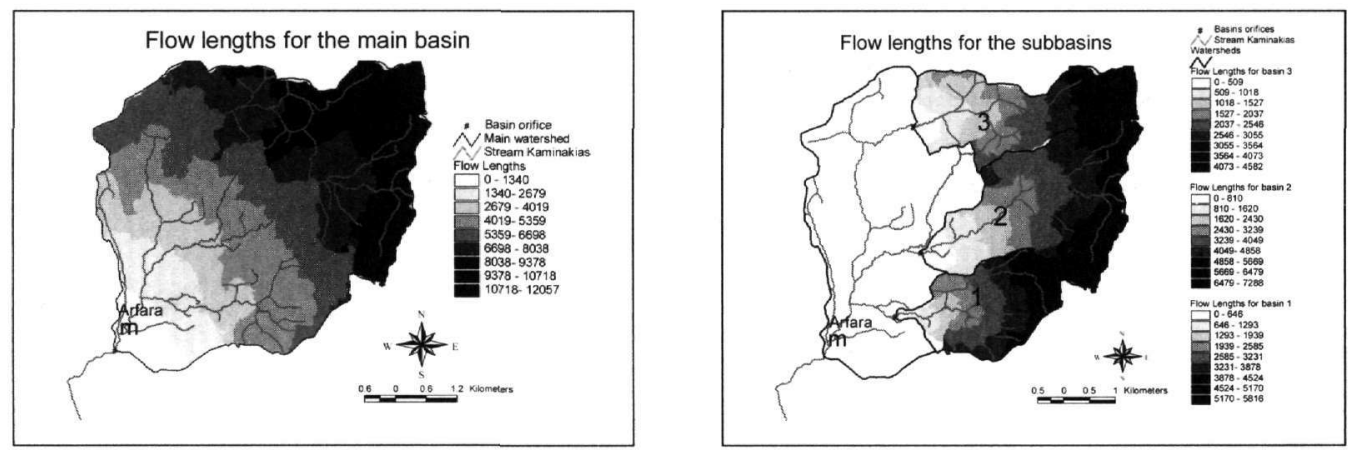

Figure 6 - Flow length maps for the Kaminakias basin and the 3 sub-basins

\section{Instantaneous Unit Hydrographs (IUH)}

Based on the above mentioned the construction of the synthetic IUH was made with the remark that the effect of the capacity of watercourse of river in the form of UH was not taken into consideration in the calculations.

In order to transform the flow length in travel time, the accumulation time tc was used. The accumulation time is the time that the water requires to travel from the most faraway watershed point of the drainage basin to the basin's lower point. Some of the more often used equations for the estimation of the accumulation time of the water has been proposed from Kirpich and Giandotti. Both of them are empiric and have certain restrictions in their application as the area and the mean slope gradient. According to the admissions of the Kirpich equation, the values that result are indicative of the surface flow in places without or low plant cover. The vegetation imports a factor of time delay and consequently for the cases of hydrologic basins the times of concentration must be doubled (x2), so that they approach better the real conditions.

In this paper the Kirpich equation (1940) was used and 2 multiplied the values that were calculated for the reasons that were already explained. Moreover comparison and verification of these values with the Giandotti equation was made (Table 1).

Table 1 - The concentration times according to the application of Kirpich and Giandotti equations

\begin{tabular}{l|cc} 
& tc (Kirpich) & tc (Giandotti) \\
\hline Main basin & $2.18 \mathrm{~h}$ & $2.55 \mathrm{~h}$ \\
Basin 1 & $1.099 \mathrm{~h}$ & $0.761 \mathrm{~h}$ \\
Basin 2 & $1.74 \mathrm{~h}$ & $0.922 \mathrm{~h}$ \\
Basin 3 & $0.741 \mathrm{~h}$ & $0.65 \mathrm{~h}$
\end{tabular}




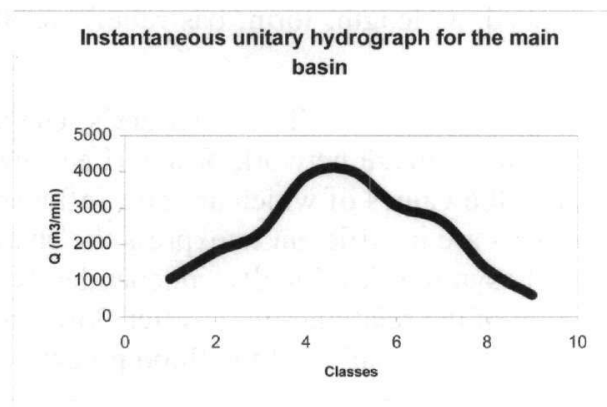

Instantaneous unitary hydrograph for basin 2

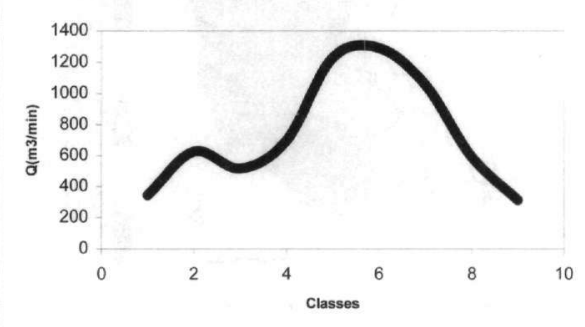

Instantaneous unitary hydrograph for basin 1

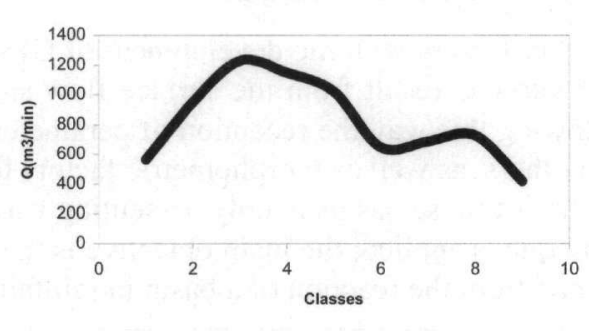

Instantaneous unitary hydrograph for basin 3

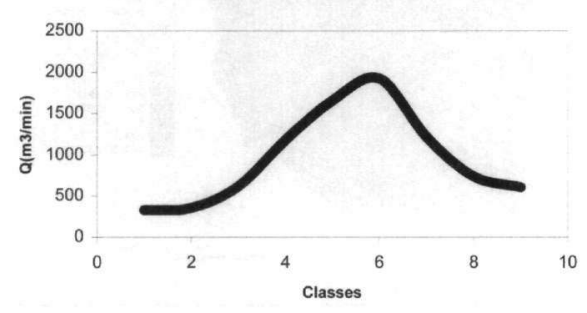

Figure 7 - The Instantaneous Unitary Hydrographs (IUH) for the selected basins. The pics of the Hydrographs indicate that there are large regions in the same basins that discharge simultaneously

From Table 1 it is obvious that there are not notable divergences all the times and primarily the ap plication of Giandotti equation gives smaller times than Kirpich ones, with the exception of the ma in basin that gives longer time and this possibly is due to the longer length of the main watercourse of the main basin. Following we shall use the results of the application of the Kirpich equation. Th us we considered as accumulation times, for each basin, the Kirpich times as they are shown in the Table 1. Following, we applied transformation of the number of pixels in area, by multiplying thei $\mathrm{r}$ number with the dimensions of pixels $\left(4 \mathrm{~m} \mathrm{x} 4 \mathrm{m=16} \mathrm{m}^{2}\right)$ and transformed the flow length in trav el time of flow direction, based on the accumulation time. Finally, the area of the basins was transf ormed in volume with the application of the Instantaneous Unitary Rain $(1 \mathrm{~mm}$ or $1 \mathrm{~cm})$. From the above mentioned times result the times $\mathrm{t}_{\mathrm{t}}$, which will be the specific time bases for each hydrograp $\mathrm{h}$. The volumes that correspond in concrete time intervals are divided with these specific time base $\mathrm{s}$ giving the following results: $14.57 \mathrm{~min}$ for the main basin, $7.32 \mathrm{~min}$ for the basin $1,11.63 \mathrm{~min}$ for the basin 2, and $4.94 \mathrm{~min}$ for the basin 3 .

Based on all the abovementioned came out the Instantaneous Unitary Hydrographs for the selected basins (Fig. 7). The most interesting IUH are these concerning the main basin and the basin 3, because they show distinct pics, whereas the hydrographs of basins 1 and 2 are of minor interest. The characteristic sharp form of the pics of the IUH is interpreted that in these basins there are sites with large area compared to the others, that in case of rain they discharge simultaneously. Therefore, in case of intense rainfall, the sites in which all the tributaries that start from these areas converge will be sensitive in flood problems.

\section{Discussion - Conclusions}

Regarding the profiles (gradient and stream power) that were constructed for Kaminakias catchment the following conclusions came out: 
There is a good coincidence of the sites that stream power and gradient of the watercourse increase abruptly. This means that from these sites and downstream the area might be sensitive to flood phenomena. The abrupt gradient and stream power increase at these sites is due to the active tectonics of the area as the majority of them are located at the cross-section points of the watercourse and the Pidima-Arfara active fault zone.

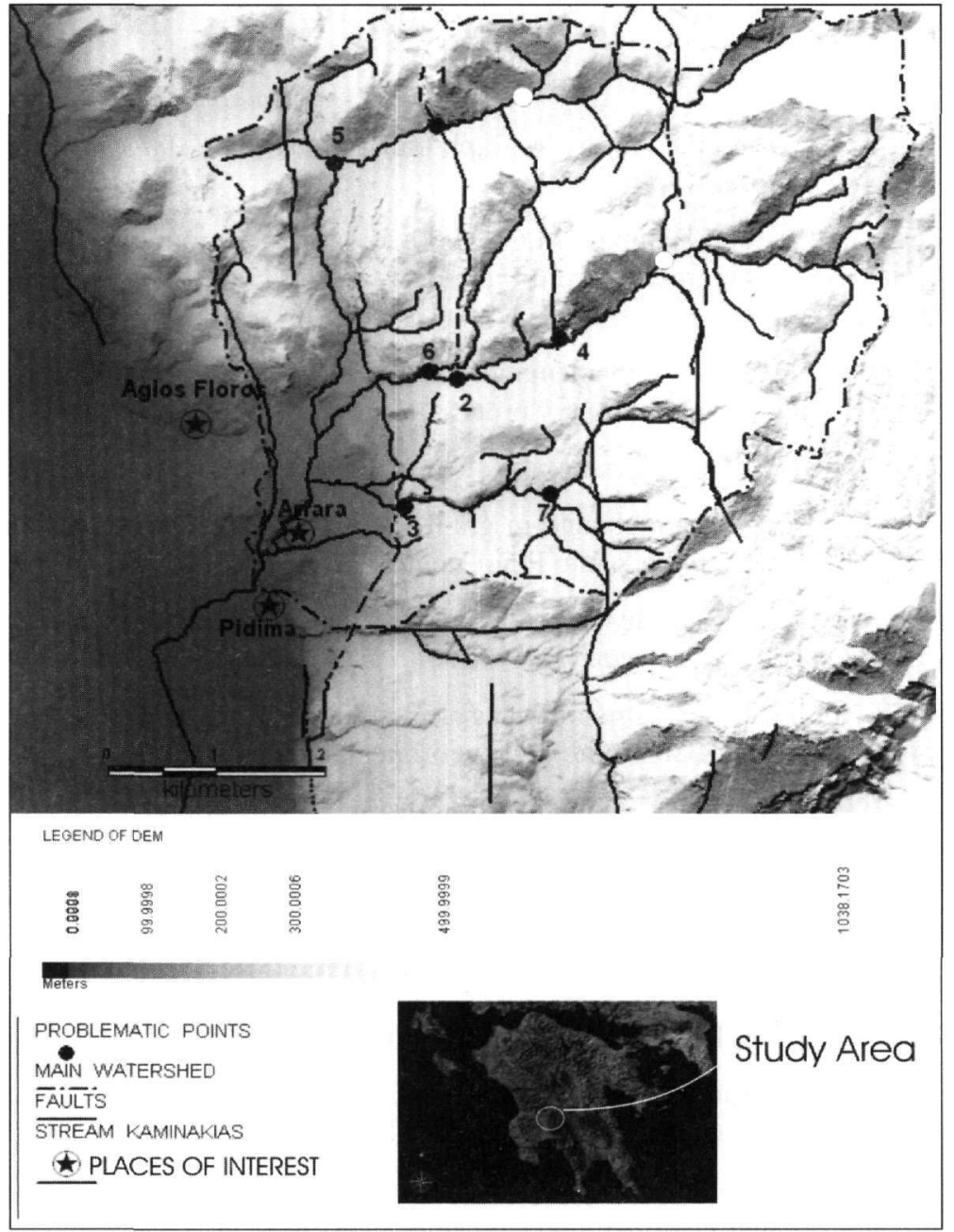

Figure 8 - The areas that increase the possibility for flash floods in the area as it comes out from the hydrological simulation and the stream power-gradient profiles that were constructed. The white dots represent areas of minor importance

In order to cross-check the abovementioned results and to confirm that the characterized sensitive sites in flash floods are correct, we implied a hydrological simulation, constructing hydrographs for the basins occurring in the study area. From those hydrographs it was found out that the sites in which the possibility for flash floods in the study area increases, are the sites with high gradient values and great stream power change of stream Kaminakias watercourse.

From the sites defined using both methodologies (stream gradient - stream power and hydrological simulation) and down stream the study area is sensitive to flood phenomena and mostly the area located downstream of the sites 3,5 and 6, where the relief is very low and almost planar and the villages Arfara and Pidima occur. Furthermore, in this area large carbonatic blocks occur either in the watercourse or on the lower terrace of the Kaminakias catchment. 
It has to be mentioned that all sensitive to flood sites are located close and downstream of the activ e faults. With regard to the most suitable localities that can be done flood preventing works in the $\mathrm{s}$ tudy area, are, which are located along Kaminakias stream and upstream from the black numbered circles in Fig. 8. Furthermore, all sensitive sites and the upstream area are located on the carbonate $\mathrm{s}$ of Tripolis unit, and the flood-preventing works must be done in the area located upstream of site s 1,2 , and 3 .

\section{References}

Clark, C.O., 1945. Storage and the unit hydrograph transactions, Bull. American Soc. Civil Enginners, $110,1419-1488$.

Grant, G.A., Swanson, F.J., and Wolman, M.G., 1990. Pattern and origin of stepped-bed morphology in high gradient streams, Western Cascades, Oregon, Bull. Geological Society of America $102,340-352$.

Hiroo Ohmori, 1991. Change in the mathematical function type describing the longitundinal profile of a river through an evolutionary process, Journal of Geology, 99, 97-110.

Knighton, A.D., 1999. Downstream variation in stream power. Geomorphology, 29, 293-306.

Koichiro Inoue, 1991. Downstream change in grain size of river bed sediments and its geomorphological implications in the Kanto Plain, central Japan, Journal of Geology, 99, 97-110.

Lee, K.T., 1998. Generating design hydrographs by DEM assisted geomorphic runoff simulation: a case study, Journal of American Water Resources Association 34/2, 375-384.

Leece, S.A., 1997. Nonlinear downstream changes in stream power on Wisconsin's Blue River, Annals of the American Association of Geographers, 87, 471-486.

Magilligan, F.J., 1992. Thresholds and the spatial variability of flood power during extreme floods, Geomorphology, 5, 373-390.

Mariolakos, I., Fountoulis, I., and Ladas, I., 2001. Paleogeographic evolution of SW Peloponnese during Quaternary, Proc. $9^{\text {th }}$ Congr. Geol. Soc. Greece, Bull. Geol. Soc. Greece, XXXIV/1, 37-45. (in Greek)

Mimikou, M.A., and Mpaltas, E.A., 2001.Technical hydrology, editions NTUA, Athens, 263.

Montgomery, D.R., and Buffington, J.M., 1997. Channel-reach morphology in mountain drainage basins, Bul. Geological Society of America 109, 596-611.

Nanson, G.C., and Hean, D., 1985 . The west Dapto flood of February 1984 : rainfall characteristics and channel changes, Australian Geographer 16, 249-258.

Reinfelds Ivars, Cohen Tim, Batten Paul, Brierley Gary, 2004. Assessment of downstream trends in channel gradient, total and specific stream power: a GIS approach, Geomorphology, 60, 403-416.

Sambaziotis, E., 2005. Study for the confrontation of floods in the Pidima -Arfara area (Messinia, SW Peloponnese, Greece) and for the possibility of the occurring karstic aquifer recharge. Msc Thesis, University of Athens, Faculty of Geology and Geonvironment. (in Greek)

Sherman, L.K., 1932. Stream flow from rainfall by unit-graph method, Engineering news-record, 108, vol. 14, 501-506.

Sshumm, S.A., 1985. Pattern of alluvial rivers, Annual Review of Earth and Planetary Sciences, $13,5-7$. 
Voudouris, K., 1999. Analysis of extreme rainfall events of the Alexandroupolis meteorological station, Thracean Gold Mining S.A., Perama Project, Athens.

Wilson, P.J., 2000. Terrain-based descriptions of Earth surface and atmospcheric processes.

Wilson, P.J., and Gallant, C.J., 2000. Digital Terrain Analysis. 